This item was submitted to Loughborough's Research Repository by the author.

Items in Figshare are protected by copyright, with all rights reserved, unless otherwise indicated.

\title{
Transient high-frequency elasto-acoustic response of a vehicular drivetrain to sudden throttle demand
}

PLEASE CITE THE PUBLISHED VERSION

PUBLISHER

Professional Engineering Publishing / @ IMECHE

VERSION

VoR (Version of Record)

LICENCE

CC BY-NC-ND 4.0

\section{REPOSITORY RECORD}

Vafaei, S., M.T. Menday, and Homer Rahnejat. 2019. "Transient High-frequency Elasto-acoustic Response of a Vehicular Drivetrain to Sudden Throttle Demand". figshare. https://hdl.handle.net/2134/4792. 
This item was submitted to Loughborough's Institutional Repository (https://dspace.lboro.ac.uk/) by the author and is made available under the following Creative Commons Licence conditions.

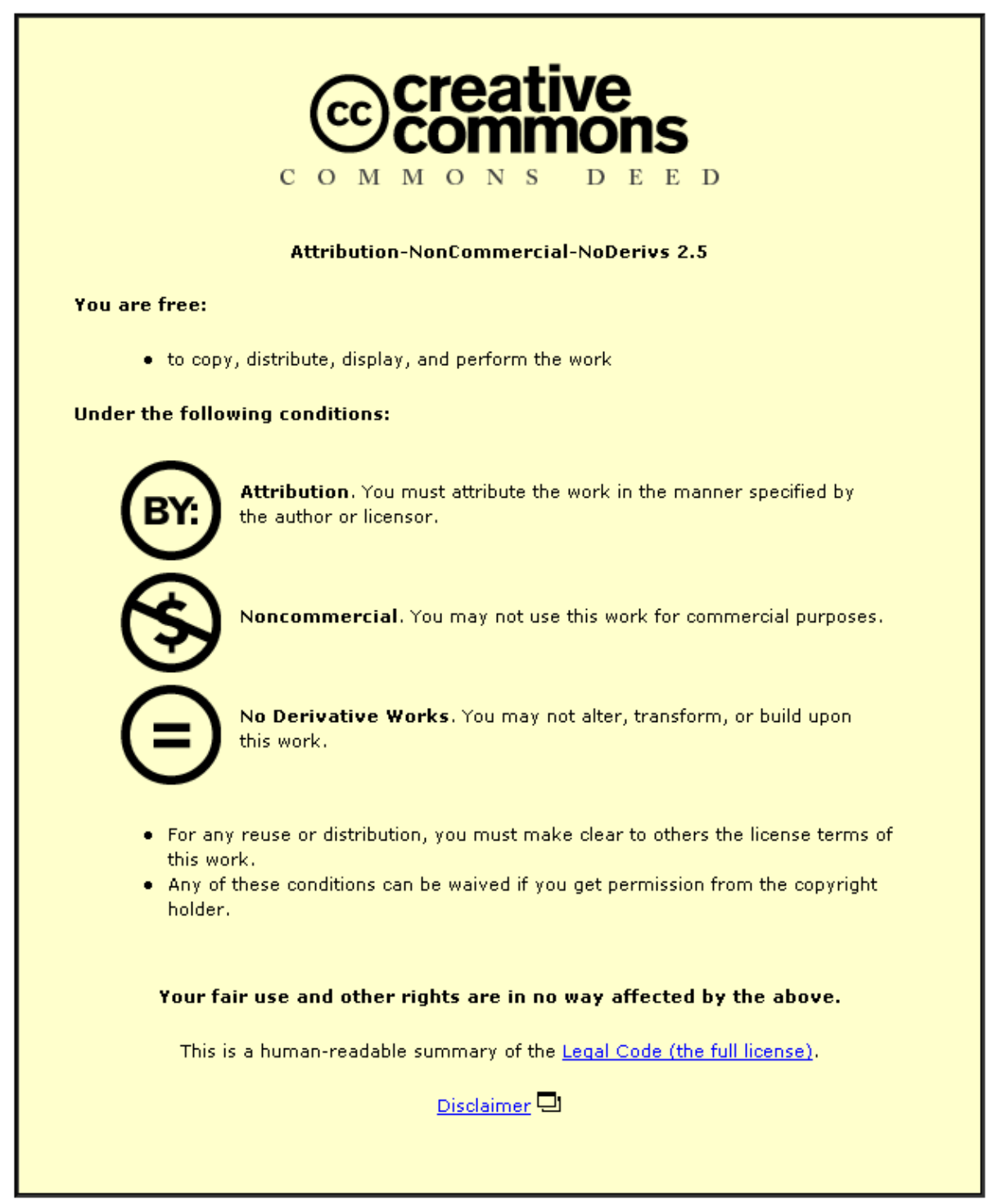

For the full text of this licence, please go to: http://creativecommons.org/licenses/by-nc-nd/2.5/ 


\title{
Transient high-frequency elasto-acoustic response of a vehicular drivetrain to sudden throttle demand
}

\author{
S Vafaei ${ }^{1}, \mathbf{M}$ Menday $^{2}$ and $\mathbf{H}$ Rahnejat $^{1 *}$ \\ ${ }^{1}$ Wolfson School of Mechanical and Manufacturing Engineering, Loughborough University, Loughborough, UK \\ ${ }^{2}$ Powertrain Engineering, Ford Engineering and Research Centre, Dunton, UK
}

\begin{abstract}
This paper presents an experimental investigation of the high-frequency structural response of vehicular powertrain systems when subjected to sudden surge in output torque demand as in throttle tip-in from coast to drive condition. The lightly damped drivetrain system has many lash zones represented by low stiffness components and thin shell elements with large modal densities. The highfrequency noise and structural dynamic modes excited under impact conditions through low lash rate zones are of short transitory nature but a major concern to vehicle drivers and other road users alike. An investigation of the root cause of these transitory events requires state-of-the art signal processing techniques at reasonably high sampling rates. This paper presents the results of an investigation into the driveline clonk problem and establishes the relationship between this phenomenon and the lowfrequency shuffle of the vehicle.
\end{abstract}

Keywords: vehicular powertrain systems, transient high-frequency response, drivetrain shuffle, autoregression moving average method, wavelets, clonk phenomenon

\section{NOTATION}

$a_{k}$

$b_{k}$

E

$f$

$h$

$n$

$N$

$N_{\mathrm{s}}$

$p$

$q$

$R_{x x}(\tau)$

$S_{p}^{\mathrm{fb}}$

$t$

$x(t)$

$\widetilde{x}$

$x^{*}$

$x^{\mathrm{T}}$

$\|x\|$ autoregressive coefficients

moving average coefficients

expectation

frequency

coefficient

input to filtration process

number of samples for a random process

number of given data segments

autoregression order

order for the moving average process

autoregression function

sum of the forward or backward squared

prediction errors

time

time series function

reversal of $x$

complex conjugate of $x$

transpose of $\boldsymbol{x}$

Euclidean norm of $\boldsymbol{x}$ $\alpha$

$\boldsymbol{\gamma}_{p}, \boldsymbol{\gamma}_{p}^{\prime}$

$\delta_{m}$

$\varepsilon_{p}(n)$

$\varepsilon_{p}^{\mathrm{b}}(n)$

$\rho(f)$

$\nabla_{a}$ unspecified element of a vector or a matrix

forward and backward reflection coefficients for order $p$ delta function prediction error of the autoregression order $p$ backward prediction error for order $p$ power spectral density prediction error variance estimate gradient with respect to the vector parameter $a$

\section{INTRODUCTION}

The vehicular powertrain system comprises engine, clutch, transmission system, driveshafts, rear axle and the connections to the vehicle body. It is a complex assembly of active and reactive dynamic elements. The drivetrain is highly non-linear and lightly damped, and thus readily excited by engine and road inputs. The driveline is a source of noise, vibration and harshness (NVH) concerns with a large spectrum of response frequencies. This paper is primarily concerned with high-

The MS was received on 25 February 2000 and was accepted after revision for publication on 16 August 2000.

*Corresponding author: Wolfson School of Mechanical and Manufacturing Engineering, Loughborough University, Loughborough, Leicestershire LE11 3TU, UK. 
frequency structural-acoustic modes, commonly referred to as driveline clonk, a short-duration, audible, highfrequency transient response. This phenomenon occurs as a result of load reversals and in the presence of lashes in the system. The load reversal is usually caused by torsional impact of contacting elements as in meshing gear teeth through take-up of backlash. The lowfrequency torsional oscillations of the powertrain system are referred to as shuffle. This is coupled with the longitudinal fore and aft motions of the vehicle, known as shunt.

Traditionally, there has been an assortment of powertrain $\mathrm{NVH}$ problems that have received attention to varying degrees. These include transmission problems such as rattle and whine, driveline shuffle and vehicle shunt [1-3] and clutch judder $[\mathbf{4}, \mathbf{5}]$. Some other problematic NVH concerns have received much less attention, although their appearance has had a profound effect upon customers' perception of vehicle driveability. These include in-cycle clutch pedal vibration and the associated audible noise $(250-600 \mathrm{~Hz})$, referred to in industry as whoop [6,7], and the almost infinite structural modal response of the drivetrain components, manifested by audible, ringing, radiated noise, onomatopoeically referred to as clonk $(300-4000 \mathrm{~Hz})[\mathbf{8 , 9}$.

Although these phenomena manifest themselves in completely different manners, their underlying causes can be traced back to the structural compliance of the system components, the assembly configuration and piece-to-piece manufacturing variations. Furthermore, the source of excitation is the same (i.e. the engine power torque) [10], while the transfer paths of propagation remain distinct. However, the solution to one problem can inadvertently give rise to another and indeed accentuate the effect of other drivetrain NVH concerns. The interactions between the various NVH concerns have been largely ignored, such as the clonk response with each cycle of shuffle, when the vehicle is subjected to throttle tip-in and throttle tip-out excitations $[\mathbf{8 , 9}$ ]. Therefore, a holistic solution, involving the fundamental physical understanding of these problems, is essential and indeed long overdue.

The current available solutions have been palliative, such as the inclusion of a 'fix' on the clutch release lever to reduce the clutch pedal whoop problem [11] or foamfilled driveshafts to reduce the effect of driveline clonk [12]. These palliative solutions often lead to impairment of ideal functions, as well as increasing the cost of manufacture, while still not eliminating the problem at hand. Therefore, manufacturing competitiveness is adversely affected, not only by increased costs but also by potentially reduced custom.

Rapid throttle demands are converted to system torsional impulses. The driver requires a responsive vehicle. The ill-configured driveline, however, can excite an unwanted low-frequency torsional mode of vibration known as shuffle. Clonk may be heard on the first cycle of the shuffle response. Krenz [1], Hrovat [13] and Tobler and Tsangerides [14] have studied the relationship between audible clonk and shuffle. They have all shown that the first swing on the transient torque, which can be 2-3 times that of the steady state response, is perceived as a short-duration jerk pertaining to clonk. The initial clonk response is then followed by the shuffle cycles. In severe cases, multiple clonks may occur with each cycle of the shuffle response. The shuffle frequency is usually in the range $2-7 \mathrm{~Hz}$, with the clonk duration varying between 0.25 and $5 \mathrm{~ms}$, both depending on driveline configuration and structural materials.

Tsangerides et al. [15] have also made an important contribution in the torsional analysis of drivelines, using a lumped parameter model, including the effect of backlash using zero-rated springs. They defined tip-in jerk as the rate of change in vehicle acceleration, which may be accompanied with an audible clonk. Petri and Heldingsfeld [16] have also observed that sudden throttle change transforms into vehicle acceleration/deceleration, which may excite the system shuffle, accompanied with a hard metallic clonk. They observed such acceleration peaks at the input shaft and the differential for a rear wheel drive (RWD) vehicle.

It is therefore envisaged that the NVH spectrum will contain contributions from low frequencies, mainly owing to rigid response of the entire system to highfrequency responses due to flexure and combined torsion-deflection modes of the system components such as the driveshaft torque tubes. The low-frequency content is accounted for by shuffle and driveline angulation, and these can be obtained by rigid multi-body analysis $[15,16]$. The high-frequency content of the spectrum is expected to be due to the response of the elastic members, which can be obtained by structural modal analysis.

Arnold and Warburton [17] have shown that, for thin cylindrical shells, an infinite number of axial vibration modes, $m$, are theoretically possible, each with a corresponding number of circumferential forms, $n$. Therefore, to define a mode, the $m$ and $n$ values must be specified. Forsberg [18] used a method outlined originally by Flugge in 1934 and concluded, as did Arnold and Warburton [17], that for any given set of values $(m, n)$ there are three natural frequencies, corresponding to three mode shapes that are obtained by the solution of the cubic energy equation.

\section{DESCRIPTION OF THE EXPERIMENTAL RIG}

There have been only a few investigations of drivetrain structural-acoustic response. A recent experimental investigation by Biermann and Hagerodt [2] has shown that repeatable clonk conditions can be achieved and measured by experimental rigs that include all elements 
of a drivetrain system, subjected to an instantaneously released preload torque. Their experiments, carried out for a front wheel drive system, have pointed to a cost effective way of investigating clonk. Their approach is extended in this paper to study the clonk response of a two-piece rear-wheel driveline system.

The experimental investigation must consider the movements of every transmission and structural component along the torque path when excited by a torsional input. As high-frequency vibrations are responsible for the clonk response of the system, monitoring of accelerations of structural elements is required at a multitude of locations.

Figure 1a depicts an experimental static drivetrain rig for the typical two-piece drivetrain of a light diesel truck. The rig includes a flywheel, clutch system, transmission, a two-piece driveshaft with the centre journal bearing, the differential and the rear axle assembly including hubs and drums. Therefore, it includes all the lash zones in the drivetrain system. The transmission casing is fixed to the ground through compliant mounts, and the bell housing, the driveshafts and the rear axle are mounted upon bed plates fixed to the ground. The driveshaft assembly universal joint angles are set to nominal with no suspension test latitude. The clamped clutch transmits the flywheel impulse torque to the transmission input shaft via the torsional friction disc springs when a preload torque is released. The transmission is engaged in the second gear. Figure $1 \mathrm{~b}$ is a schematic representation of the drivetrain rig, indicating the positions of fixed piezoaccelerometers and the mounted microphones.

A specified preload torque was applied via a low inertial disc brake system to the drivetrain rig to take up all the lash elements and fully compress the clutch disc springs. The stored energy was then instantaneously released in the form of a ramp sawtooth pulse. The duration of the torsional pulse was varied in the range 80$180 \mathrm{~ms}$ as required, inducing a generated lash take-up of the order of $1-2 \mathrm{~ms}$, of sufficiently short period to excite the higher-frequency structural modes. The 1-2 ms impact was followed by approximately $30 \mathrm{~ms}$ of driveshaft tube ringing (see Fig. 2). The input ramp torque is found to be repeatable and reproducible.

The cycle can repeat itself (be it at lower oscillation levels) as cycles of shuffle, the frequency of which is around $3-7 \mathrm{~Hz}$ in this case. Very good correlation is

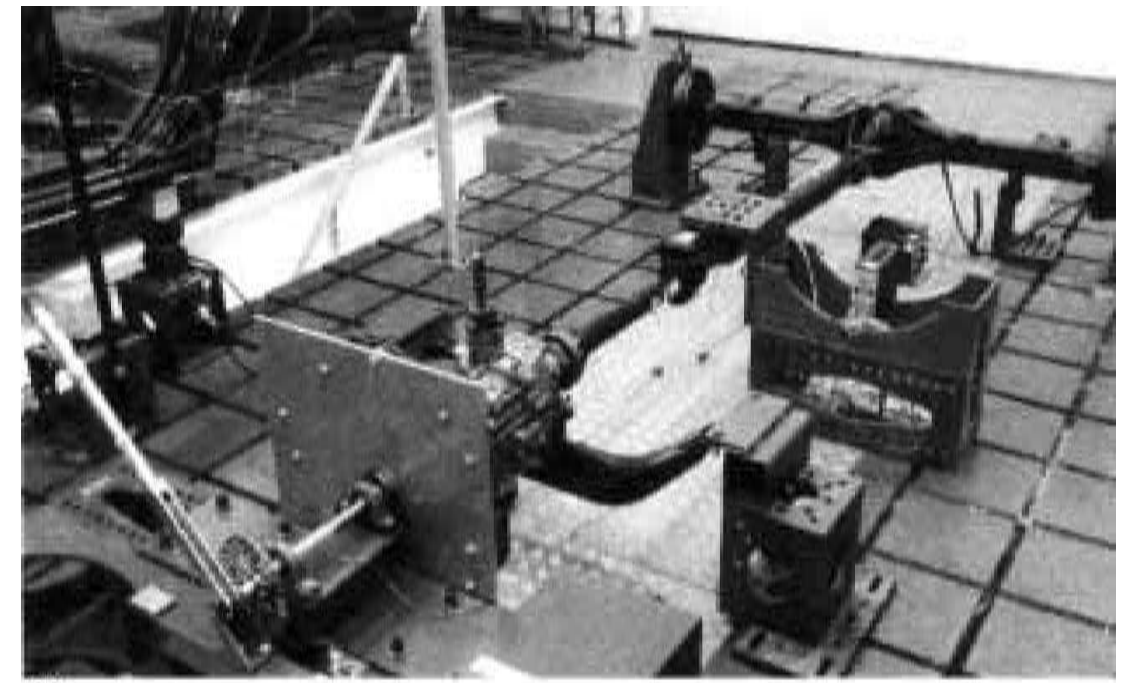

(ii)

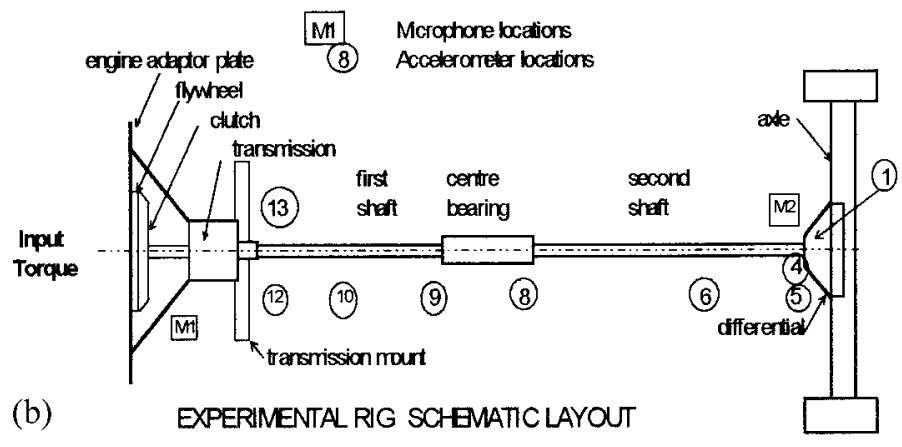

Fig. 1 (a) Experimental powertrain static test rig and (b) schematic representation of the test rig, showing the positions of the various pick-ups 


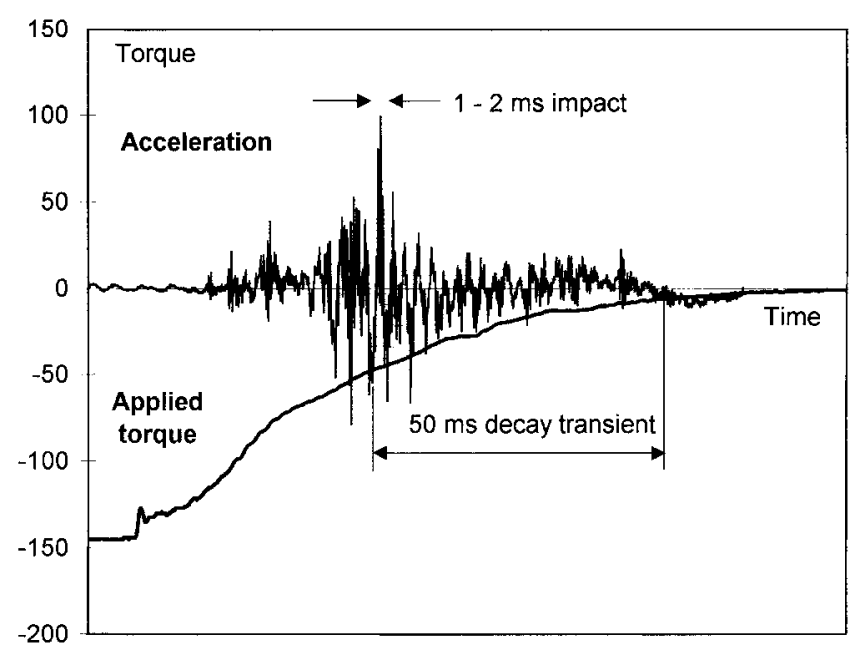

Fig. 2 Driveshaft response to the torque ramp input

found between the vibration and noise responses between the rig and vehicle condition (see Fig. 3). In Fig. 3, the results related to the experimental rig were obtained by a microphone placed near a flange which acts as a floor mounting for the transmission bell housing. The results corresponding to the road test data were obtained using a microphone mounted on the vehicle chassis in the vicinity of the transmission. Low-frequency vehicle shunt and the coupled powertrain shuffle can occur when the test vehicle is jacked up under the rear axle, while driven in second gear (in this case) on a chassis dynamometer. The handbrake is usually lightly applied to provide some resistance and the clutch is abruptly applied. The results are deemed acceptable if the clonk response is subjectively rated to be the same as that discerned when driving on the road.

It is thought that the driver perceives airborne noise when the door windows are lowered. Other road users also perceive the sound reverberation by the bouncing back echo from the roadside boundaries or by reflection from the parked vehicles. When the window is closed, noise is perceived as a thud through the cabin by the structure-borne noise. To corroborate this, it was found necessary to undertake acoustic modal analysis of driveshaft tubes, using a modified boundary element technique reported in reference [19]. This study corroborated the elasto-acoustic coupling in the driveshaft pieces. It was shown that the acoustic modes occur at regular intervals of $390-400 \mathrm{~Hz}$ for the rear torque tube. In fact, there are significant contributions at or around $390,780,1170$ and $1560 \mathrm{~Hz}$. These fall very close to the spectrum of vibration obtained experimentally (see Fig. 4). It can therefore be hypothesized that torque reversals may be responsible for the torsional-deflection response of elastic members (such as the driveshaft pieces) and that such torque reversals occur owing to impact loads with sudden throttle demand. To substantiate this hypothesis it was necessary to devise the experimental rig reported above.

Calibrated accelerometers are located and adhered to the various locations shown in Fig. 1b. In order to place an accelerometer pick-up at the ring gear position, the axle was tested without lubrication. Microphones were also placed at the transmission and the rear axle locations. Twelve-channel data acquisition was carried out at a data sampling rate of 12500 samples per second, corresponding to a time interval of $80 \mathrm{~ms}$.

Figure 4 shows a typical spectral composition for a driveshaft tube, obtained by an impact test and indicating high-frequency contents in the range $1.5-5 \mathrm{kHz}$. In fact, significant contributions occur in the 1-1.5, 2.25 and $2.75-3.25 \mathrm{kHz}$ regions for the front tube and in the 1.75 , $2.5-2.75$ and $3.5-3.75 \mathrm{kHz}$ regions for the rear tube. Note that the figure indicates three different spectra. One is referred to as the baseline response for unfilled hollow tubes. The other two indicate the reduction in amplitudes of vibration when the tubes are either filled with foam or wound with steel strip.

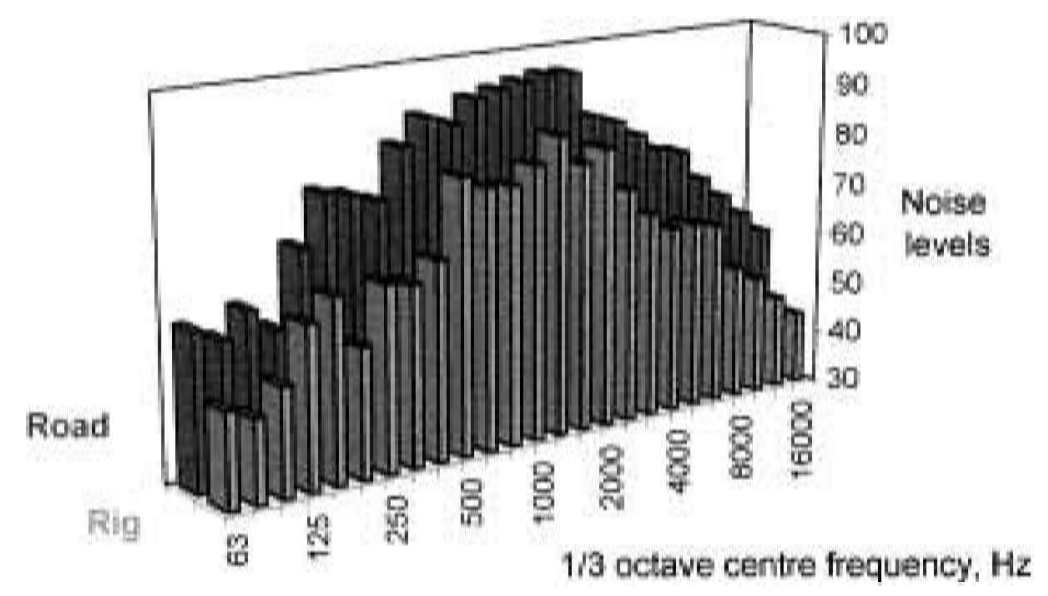

Fig. 3 Conformance of the experimental rig results with vehicle condition 


\section{Log response}

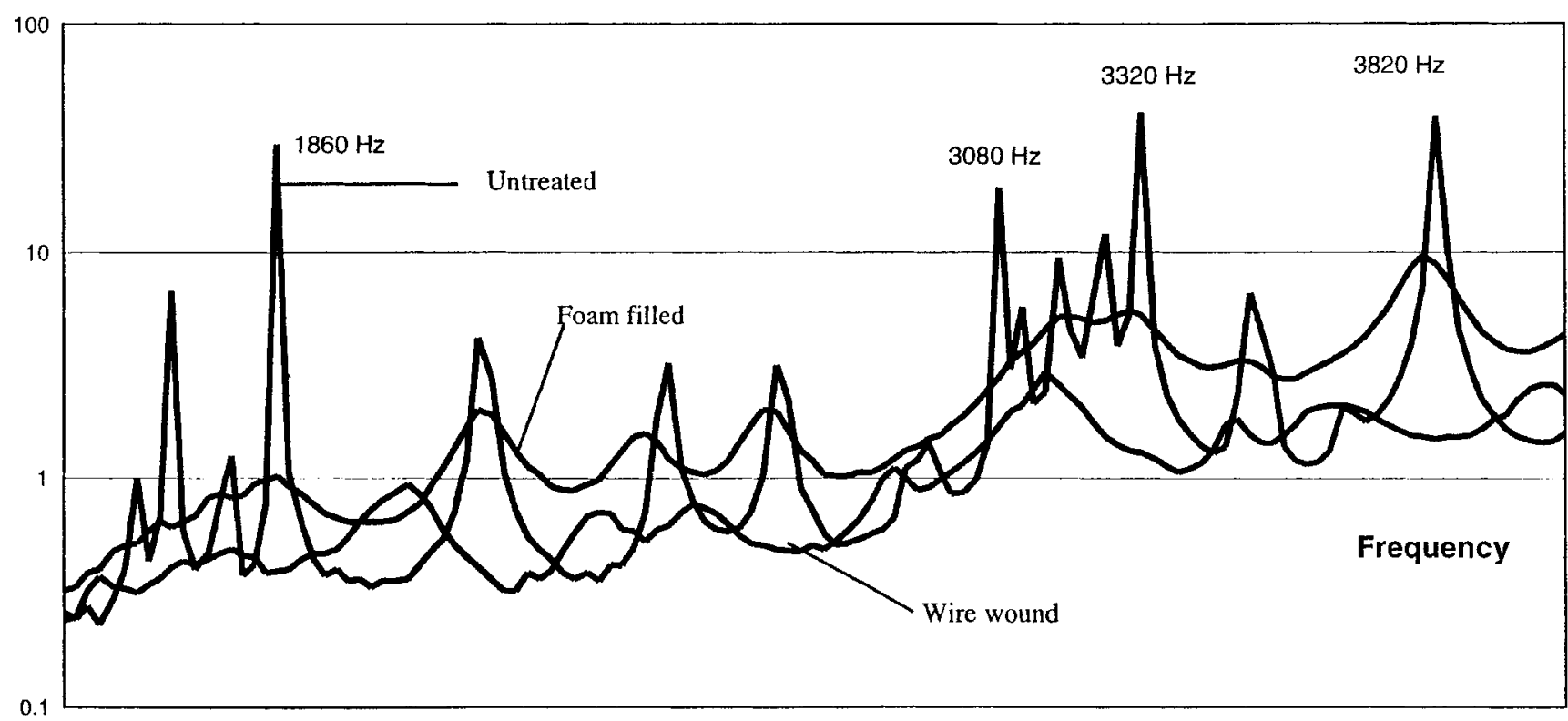

Fig. 4 Experimental spectral response of the rear driveshaft tube

\section{METHOD OF SIGNAL PROCESSING}

\subsection{Estimation of power spectral density}

Estimation of the power spectral density (PSD), or simply the spectrum of discretely sampled deterministic or stochastic processes, is usually based upon procedures that employ Fourier transformation. This approach is computationally efficient in many applications, but there are some inherent limitations. The most prominent shortcoming of this approach is that of frequency resolution, i.e. the ability to distinguish between the spectral contributions. The other limitation is due to the implicit windowing of the sampled data, which occurs when processing with fast Fourier transformation (FFT). Windowing can manifest itself as 'leakage'; the spectral domain energy in the main lobe of a spectral response leaks into side lobes, obscuring and distorting other spectral contributions which may be present there. These limitations become significant when studying the short transient response of systems, particularly at high frequencies. It can then be concluded that, for 'stiff' systems with widely split eigenvalues, spectral decomposition techniques based upon FFT are unsafe.

For the case of stationary processes, the autocorrelation function can provide the basis for spectral analysis, rather than the random process $x(t)$ itself. Therefore

$$
R_{x x}(\tau)=E\left[x(t+\tau) x^{*}(t)\right]
$$

The autocorrelation function $R_{x x}(\tau)$ for a stochastic widesense discrete process $x_{n}$ is defined in this paper as the expectation of the product $x_{n+k} x_{n}^{*}$, where $x_{n}$ is assumed to have a zero mean value. The Wiener-Khinchin theorem relates the autocorrelation function via the Fourier transform to the power spectral density (PSD), $\rho(f)$, as

$$
\rho(f)=\int_{-\infty}^{\infty} R_{x x}(\tau) \mathrm{e}^{-\mathrm{j} 2 \pi f \tau} \mathrm{d} \tau
$$

In practical circumstances, the statistical autocorrelation function is not usually known. Thus, an additional assumption is often made by considering the random process as ergodic in the first and second moments. This property allows for the substitution of time averages for ensemble averages. For an ergodic process, therefore, the statistical autocorrelation function may be represented as

$$
R_{x x}(\tau)=\lim _{T \rightarrow \infty} \frac{1}{T} \int_{-T}^{T} x(t+\tau) x^{*}(t) \mathrm{d} t
$$

An obvious companion autocorrelation estimate, based upon the above equation, is the unbiased estimator

$$
R_{x x}(m)=\frac{1}{N-m} \sum_{n=0}^{N-m-1} x_{n+m} x_{n}^{*}
$$

for $m=1,2, \ldots, M$, where $M \leqslant N-1$.

The negative lag estimates are determined from the positive lag estimates, in accordance with the conjugate symmetric property of the autocorrelation function of a stationary process, as

$$
R_{x x}(-m)=R_{x x}^{*}(m)
$$


The autocorrection estimate proposed by Jenkins and Watts [20] and Parzen [21, 22] tends to have a lesser least-square error than equation (4) and is employed in the current analysis as

$$
R_{x x}(m)=\frac{1}{N} \sum_{n=0}^{N-m-1} x_{n+m} x_{n}^{*}
$$

where $n=0,1,2,3, \ldots, M$.

\subsection{The Autoregression moving average (ARMA) method}

The short transient high-frequency responses such as the clonk phenomenon described above should be investigated using the autoregression moving average (ARMA) method. In this case the model assumes that a time series, $x_{n}$, can be represented as the output of a $p$-pole and $q$-zero filter, excited by white noise:

$$
x_{n}=-\sum_{k=1}^{p} a_{k} x_{n-k}+\sum_{k=0}^{a} b_{k} n_{n-k}
$$

The poles of the filter are assumed to be within the unit circle of the $Z$ plane. This most general linear model is termed an ARMA model. Once the parameters of the ARMA $(p, q)$ model are identified, their spectral estimate can be obtained as

$$
\rho_{f}(f)=\frac{\sigma^{2} \Delta t\left|1+\sum_{k=1}^{a} b_{k} \mathrm{e}^{\mathrm{j} 2 \pi f k \Delta t}\right|^{2}}{\left|1+\sum_{k=1}^{p} a_{k} \mathrm{e}^{\mathrm{j} 2 \pi f k \Delta t}\right|^{2}}
$$

The relationship for the ARMA parameters with the autocorrelation function is obtained by multiplying the above equation by the term $x_{n-k}^{*}$ and taking the expectation $E\left[n_{n} x_{n-k}^{*}\right]$ to yield

$$
R_{x x}(l)=-\sum_{k=1}^{p} a_{k} R_{x x}(l-k)+\sum_{k=0}^{a} b_{k} R_{n k}(l-k)
$$

where $R_{n x}(k)=E\left[n_{n} x_{n-k}^{*}\right]$.

As a future input to a causal, stable filter cannot affect the present output, and as $n_{n}$ is considered as white noise, then $R_{n x}(k)=0$ for $k \succ 0$. Therefore, using the YuleWalker equations gives

$$
E\left[n_{n} x_{n-k}^{*}\right]= \begin{cases}0 & k \succ 0 \\ \sigma^{2} h_{-k}^{*} & k=0\end{cases}
$$

and the following relations can be obtained:

$$
R_{x x}(l)=\left\{\begin{array}{c}
-\sum_{k=1}^{p} a_{k} R_{x x}(l-k)+\sigma^{2} \sum_{k=0}^{q} b_{k} h_{k-1}^{*} \\
\text { for } l=0,1,2,3, \ldots, q \\
-\sum_{k=1}^{p} a_{k} R_{x x}(l-k) \\
\text { for } l=q+1, q+2, \ldots, q+p
\end{array}\right.
$$

Many different techniques have been proposed for estimation of the autoregression moving average (ARMA) parameters. These usually require matrix computation methods with or without iterative optimization. With the above Yule-Walker equations, it is possible first to estimate the autoregression (AR) parameters independently of the moving average (MA) parameters for $l \succ q$ [23]. The solution to this matrix equation can be obtained by a number of methods, including autocorrelation, covariance and modified covariance techniques, as well as by the proposed Burg [24-31] and Levinson recursive $[\mathbf{3 2}, \mathbf{3 3}]$ algorithms. The Burg method is employed in this paper. The method is set out in Appendix 1.

Once the AR parameters, $\left[a_{1}, a_{2}, \ldots, a_{p}\right]$, have been determined, an appropriate technique may be employed to determine the parameters $\left[b_{1}, b_{2}, \ldots, b_{q}\right]$. This is performed here using the Shanks method [34] (see Appendix 2).

The most important action is to determine the order of the ARMA model. In most applications, the denominator order in equation (8), $p$, is more critical than the numerator order, $q$, as this determines the number of 'modes' or natural frequencies present in the signal [35]. It is desired to obtain $p$ and $q$ through a stochastic process. A common method of achieving this is through the use of AIC (Akaike information criterion) [36-42], in order to minimize the function

$$
\operatorname{AIC}(p, q)=N_{\mathrm{s}} \ln \sigma^{2}+2(p+q)
$$

\subsection{Wavelet analysis}

With wavelet analysis, an arbitrary square integrable function can be decomposed into, or constructed from, shifted and dilated versions of another square integrable function. Therefore, for a particular application, there may exist optimal wavelet representations that would behave better than others. Given that for a complex vibration signal a suitable wavelet form is identified, it may be possible to narrow around a given frequency range [43]. This is particularly useful in the cases of 
localized effects, where resonant frequencies become dominant with given events [44].

It is possible to decompose any arbitrary signal $f(x)$ into its wavelet components. The approach is the same as in harmonic analysis, except that, instead of breaking a signal down into harmonic functions of different frequencies, the signal is broken down into wavelets of different scale (different level) and different positions along the abscissa. For example, consider a finite length of a signal $f(x)$, assumed to be known over the interval $0 \leqslant x<1$. The signal can be represented as a constant level (for all wavelets of levels less than zero), plus wavelets of all levels above zero, and thus

$$
\begin{aligned}
f(x)= & a_{0}+a_{1} w(x)+a_{2} w(2 x)+a_{3}(2 x-1)+a_{4} w(4 x) \\
& +a_{5} w(4 x-1)+a_{6} w(4 x-2)+a_{7} w(4 x-3) \\
& +a_{8} w(8 x)+a_{9} w(8 x-1)+a_{10} w(8 x-2)+\cdots
\end{aligned}
$$

$$
f(x)=a_{0}+\sum_{j=0}^{\infty} \sum_{k=0}^{2 j-1} a_{2^{j}+k} w\left(2^{i} x-k\right), \quad 0 \leqslant x \prec 1
$$

The discrete wavelet transform (DWT) is an algorithm for computing $a_{0}, a_{2^{j}+k}$, where $f(x)$ is sampled at equally spaced intervals over $0 \leqslant x \prec 1$. The DWT algorithm was first proposed by Mallat [45] and is called Mallat's pyramid algorithm or sometimes Mallat's tree algorithm.

The wavelet 'level' is determined by the number of wavelets fitting into the unit interval $x=0-1$. At level zero there is a $2^{0}=1$ wavelet, while at level 1 there are $2^{1}=2$ wavelets and so on. The mathematical basis for wavelet transform is described more fully in references [46] to [49].

Wavelet analysis involves a fundamentally different approach. Instead of seeking to break down a signal into its harmonics, which are global functions that continue indefinitely, the signal is broken down into a series of local basic functions called wavelets. Each wavelet is located at a different position on the time axis and is local in the sense that it decays to zero when sufficiently far from its centre. At the finest scale, wavelets may be very short indeed, and at a coarse scale they may be very long [47]. In this analysis, the form 'db10' has been employed $[48,49]$.

\section{RESULTS AND DISCUSSION}

Figure 5 shows the low-frequency region of the power spectrum of vibration of the drivetrain system, obtained by processing the output signal from the piezoelectric accelerometer position at location 13 (i.e. the transmission flange) in Fig. 1b. There are two significant

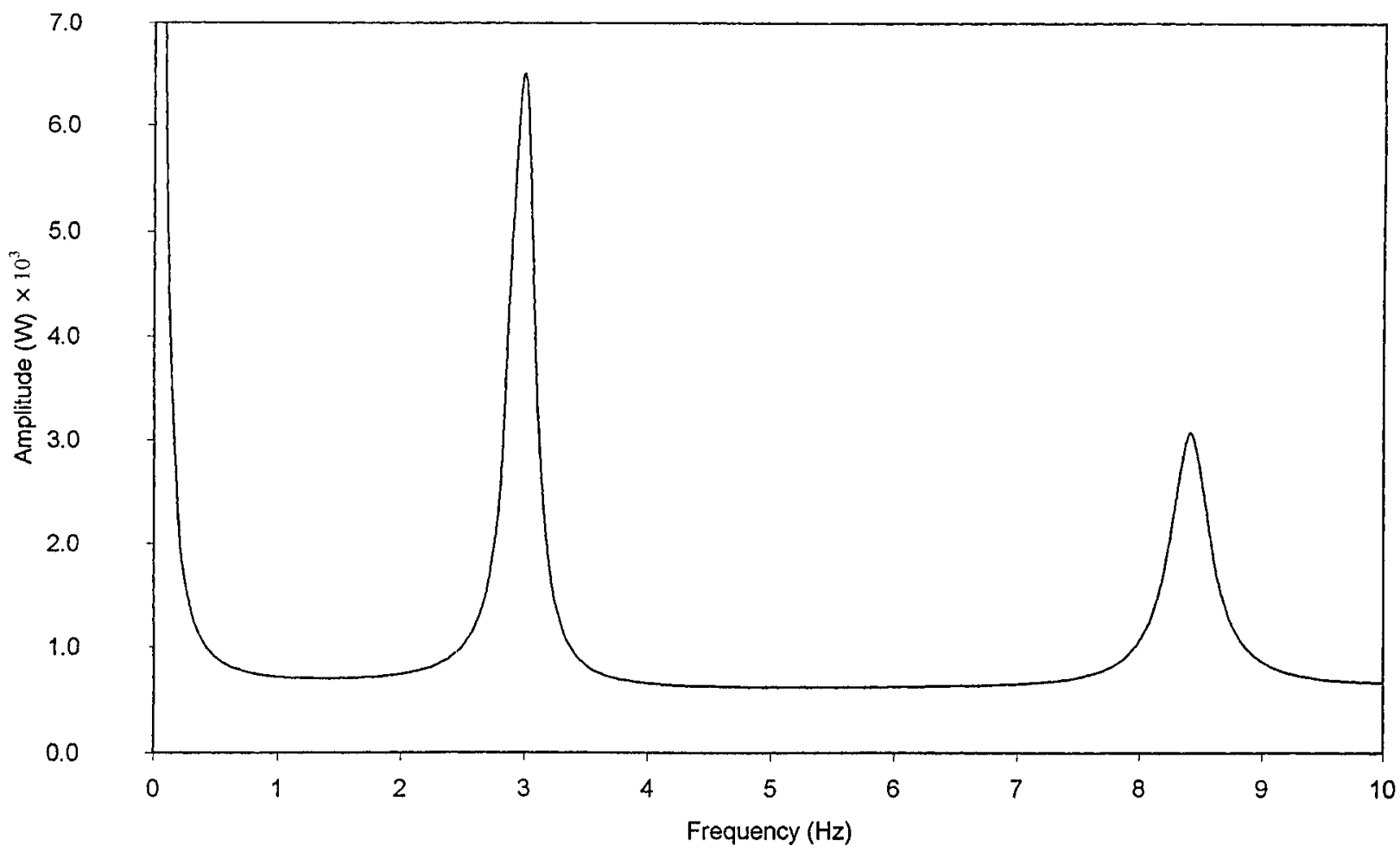

Fig. 5 Low-frequency rigid-body motions of the drivetrain system, purporting to shuffle 
peaks in this region of the spectrum: one at $3 \mathrm{~Hz}$ and the other at $8-9 \mathrm{~Hz}$. The former is the lowest rigid-body motion of the drivetrain system, commonly referred to as shuffle $[\mathbf{2}, \mathbf{3}, \mathbf{8}, \mathbf{9}, \mathbf{1 2}]$. The latter occurs as torsional oscillations of the clamped clutch inertia and is thought to be related to clutch disc springs. To verify this hypothesis, time domain analysis has been carried out using the wavelet decomposition technique described above.

Figure 6a shows the first cycle of the raw signal, while Fig. $6 \mathrm{~b}$ is the wavelet decomposition of this signal down to a frequency range of approximately $0-8.5 \mathrm{~Hz}$. It can be observed that the wavelet results show oscillations commencing from the instant of preload torque release.
It should be noted that cycles of shuffle do not commence at the outset of tests, but after a period of time. This is shown in Figs $7 \mathrm{a}$ and $\mathrm{b}$, with the raw signal and the corresponding decomposed wavelet in the range $0-3 \mathrm{~Hz}$ respectively. Cycles of shuffle commence after $0.24 \mathrm{~s}$. These observations indicate that the frequency contribution at $8.5 \mathrm{~Hz}$ in the spectrum of Fig. 5 is not related to shuffle or shunt of the experimental rig. As the preload torque is instantaneously released, with the vehicle transmission engaged in the first gear, take-up slip (judder) at the clutch friction interface is not likely to occur. However, the first mode of torsional vibration of the clamped clutch system about the friction disc springs has been found to occur in the region of $8-9 \mathrm{~Hz}$ for light
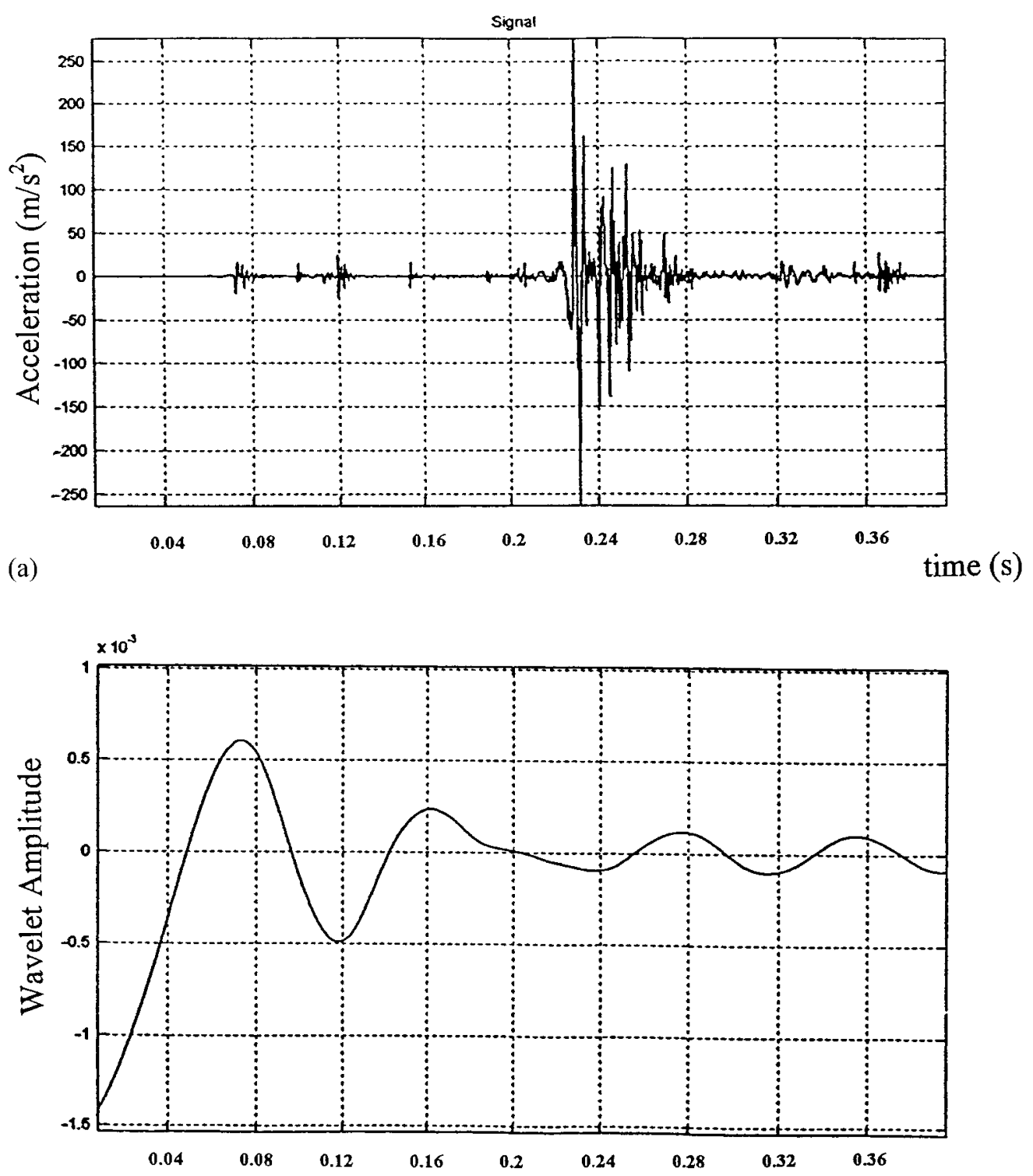

(b)

time (s)

Fig. 6 (a) Raw sampled signal from the outset of preload torque release and (b) wavelet amplitude purporting to torsional oscillations about the friction disc springs 

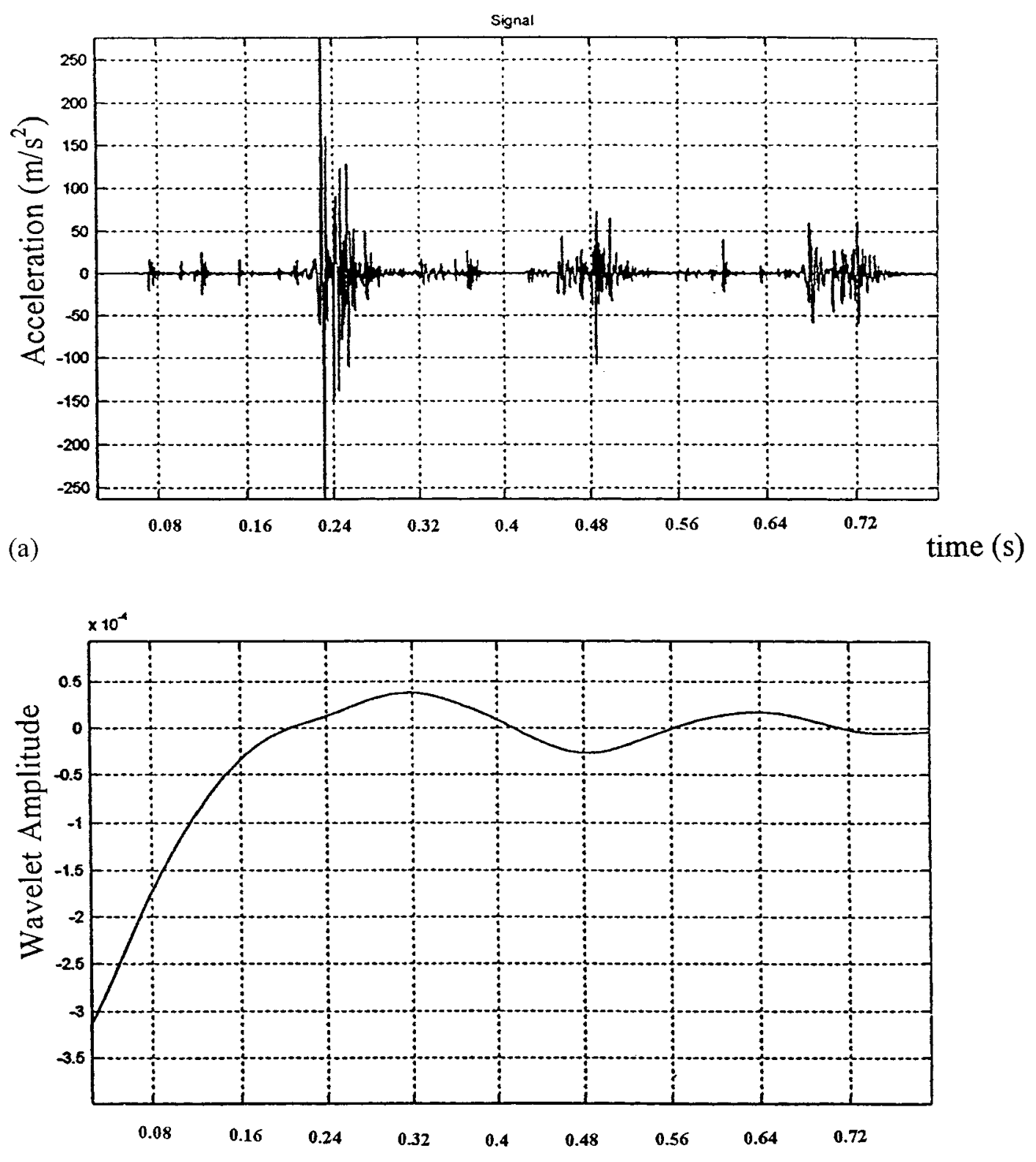

(b)

time (s)

Fig. 7 (a) Raw sampled signal for the first cycle of shuffle response and (b) wavelet amplitude corresponding to the shuffle response

trucks. Such torsional oscillations about these springs are likely to ensue prior to the cycles of shuffle of the drivetrain system.

Figure 8a shows the high-frequency structural response spectrum of vibration obtained from the same location. The first significant contribution is at approximately $520 \mathrm{~Hz}$, corresponding to the first structural mode of the bell housing, which usually occurs for most designs in the region $490-550 \mathrm{~Hz}$, depending upon the geometry of the incorporated ribs [12]. This mode corresponds to the axial and lateral contraction-expansion (i.e. the breathing mode) of the bell housing. The next significant structural mode of vibration takes place at around $700 \mathrm{~Hz}$, relating to shear deformation of the bell housing. The third mode, corresponding to the combined torsiondeflection mode of the bell housing, usually occurs in the region $1100-1300 \mathrm{~Hz}$, shown in Fig. $8 \mathrm{~b}$ at approximately $1200 \mathrm{~Hz}$. The structural deformation power is considerably higher than for the previous modes. The large values for power spectral density are due to the very low structural damping of the driveshaft tubes, subjected to an impulse torque in the region of $145 \mathrm{Nm}$. The amount of energy applied to the system by release of the preload torque is clearly large enough predominantly to excite the higher modal response of the bell housing structure.

Figure 9 shows three different spectra obtained from 

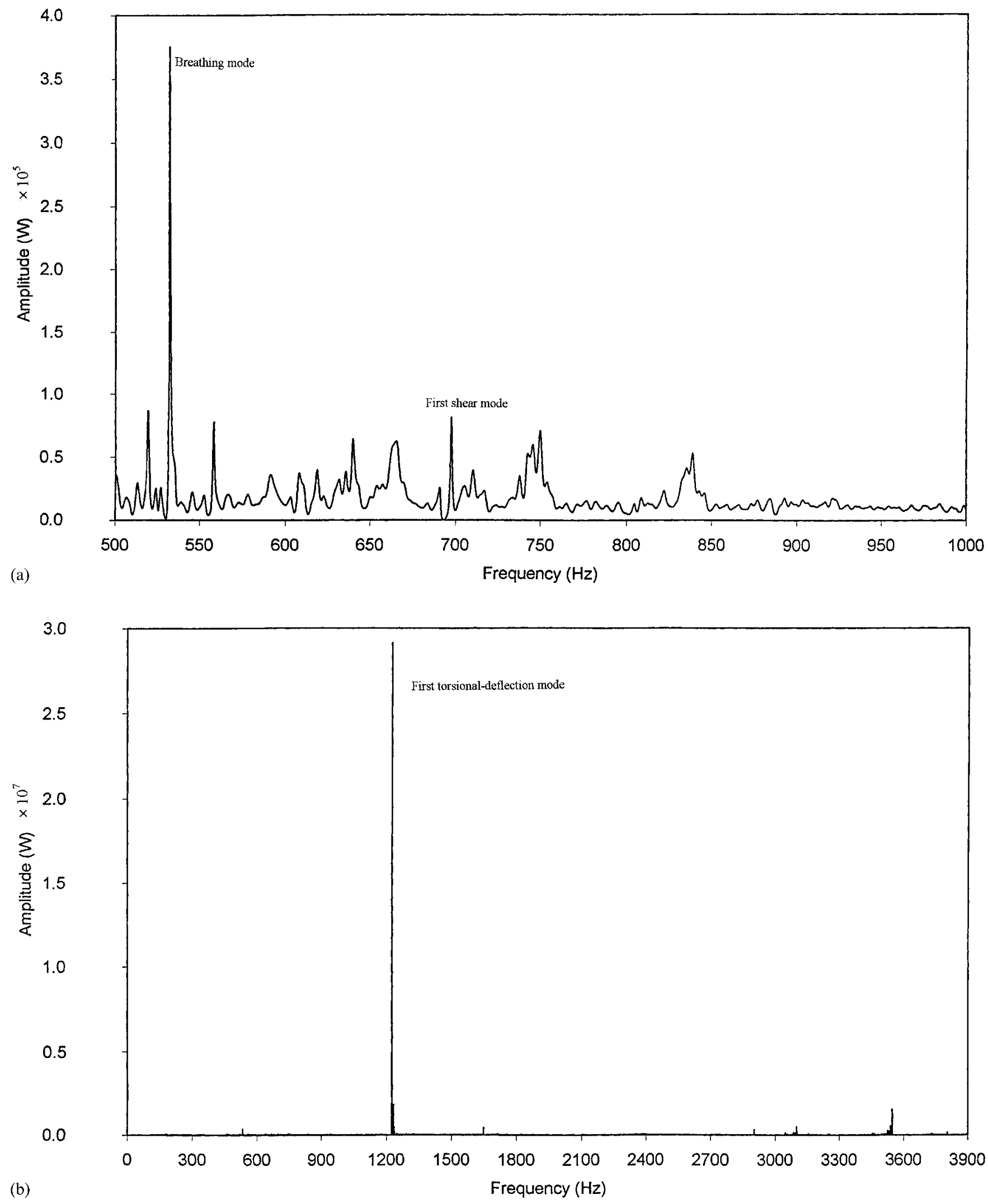

Fig. 8 Spectral composition of the bell housing 

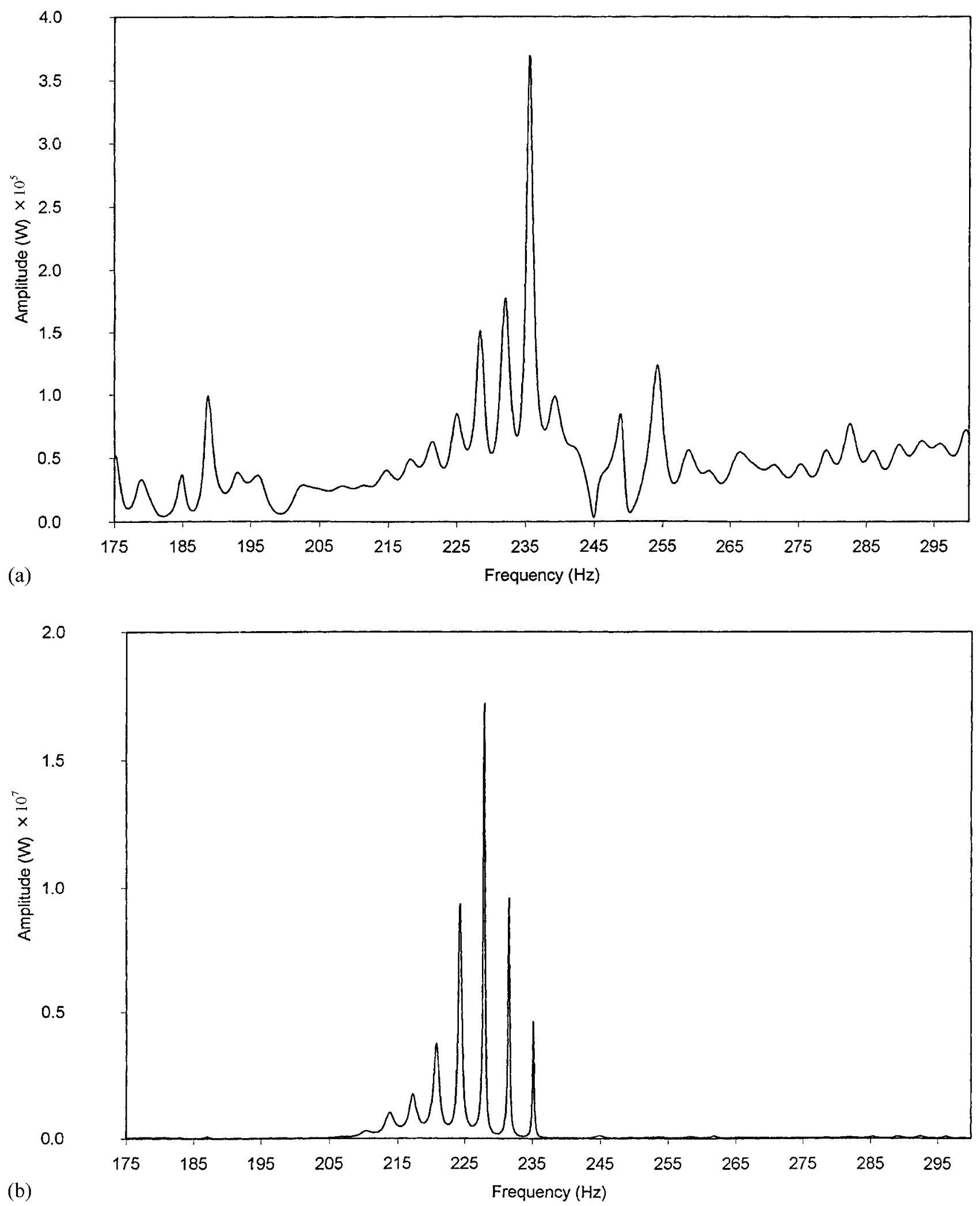

Fig. 9 (continued over)

accelerometer outputs, positioned at the beginning, midspan and at the end of the front driveshaft torque tube. All spectra are windowed in the region $175-300 \mathrm{~Hz}$ in order to verify the first coupled structural-acoustic cavity response of the tube, usually occurring in this region. Numerical analysis carried out elsewhere, using finite 


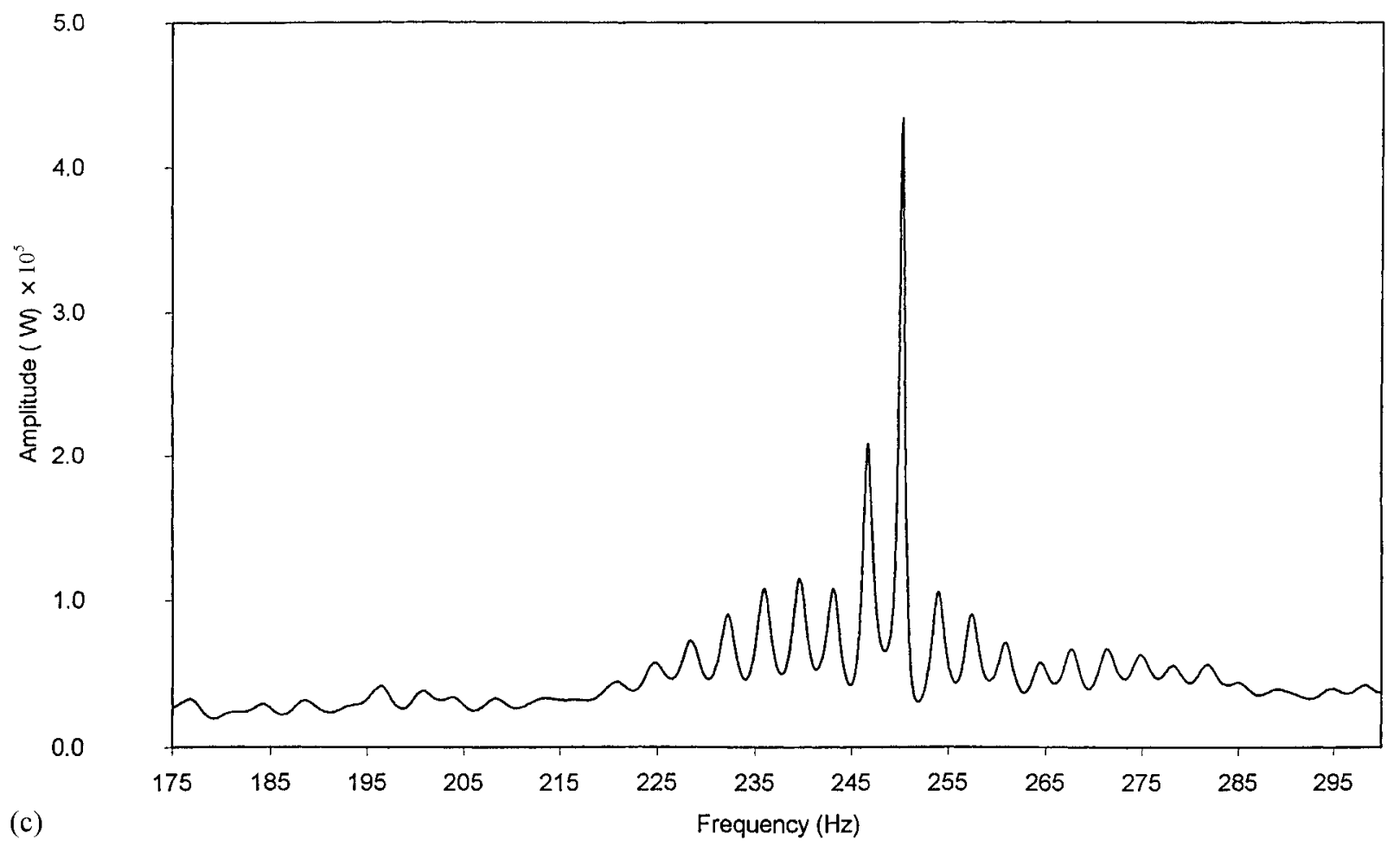

Fig. 9 First coupled structural-acoustic mode of the front driveshaft tube (a) at its transmission end, (b) at its mid-span and (c) at its splined joint end

element analysis or the boundary element method $[3,8, \mathbf{1 2}]$, has shown the first significant mode at 190$250 \mathrm{~Hz}$. It can be seen from all the three spectra that this mode of vibration takes place at around $240 \mathrm{~Hz}$. This first structural mode (i.e. at $240 \mathrm{~Hz}$ ) is almost discernible in Fig. 10, which shows the entire spectrum of vibration up

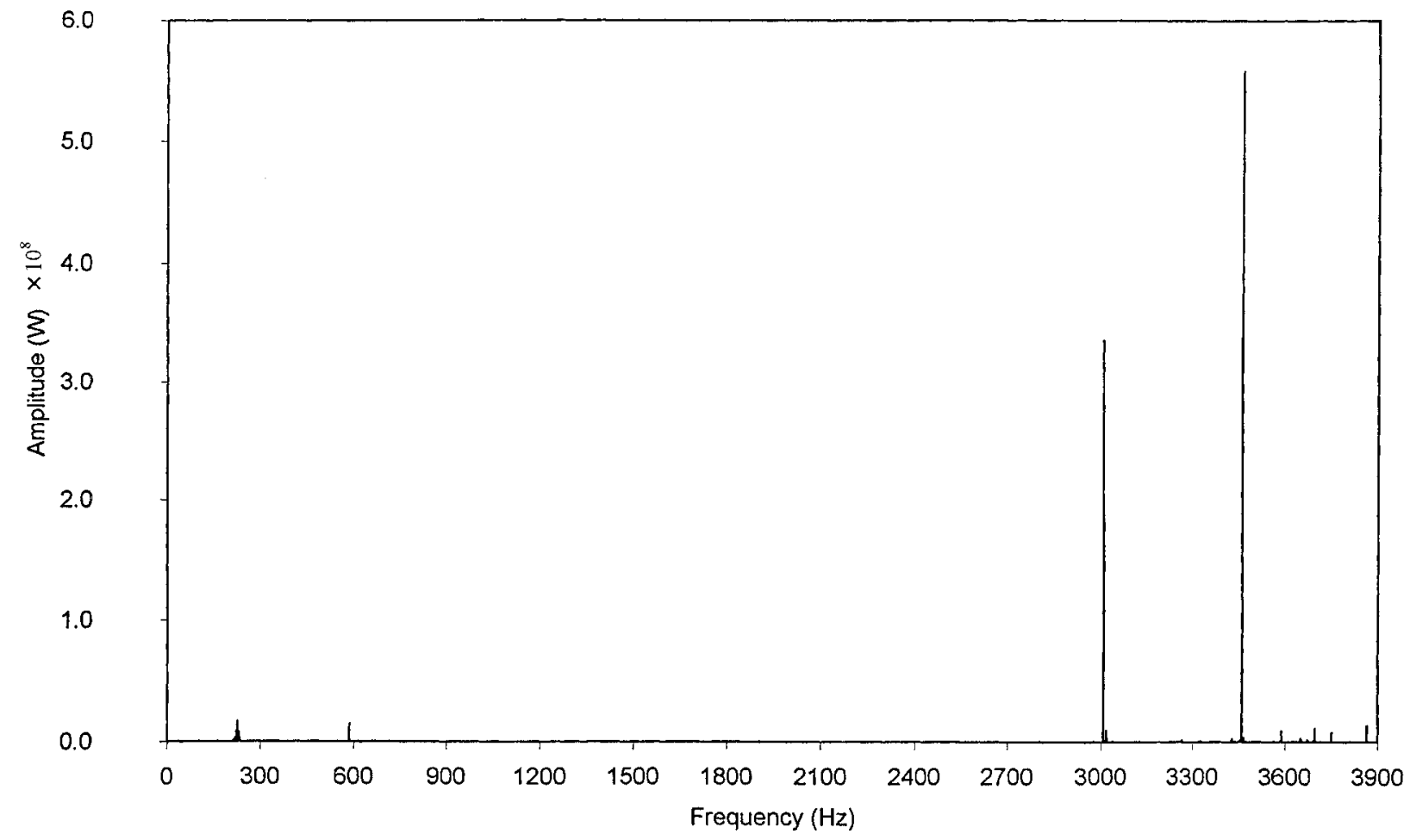

Fig. 10 Structural response spectrum of the front driveshaft tube $(0-4 \mathrm{kHz})$ 
to a frequency of $4000 \mathrm{~Hz}$. This spectrum shows much higher contributions at 3000 and $3450 \mathrm{~Hz}$. Hollow thin shell tubes, having a wall thickness in the region 1.5$3 \mathrm{~mm}$, have a very high modal density (see, for example, Fig. 4). There are many combined torsional-deflection and compression-axial structural modes. These have been obtained experimentally with hammer impact tests, as well as by finite element modal analysis [12]. The results of analyses show that the high-frequency modes are a combination of circumferential and axial structural waves that can excite the acoustic modes of the cavity [8].

Figures 11a to $\mathrm{c}$ show regions of the spectrum of vibration for the rear torque tube. The contributions in the region $350-400 \mathrm{~Hz}$ correspond to the first acoustic modes
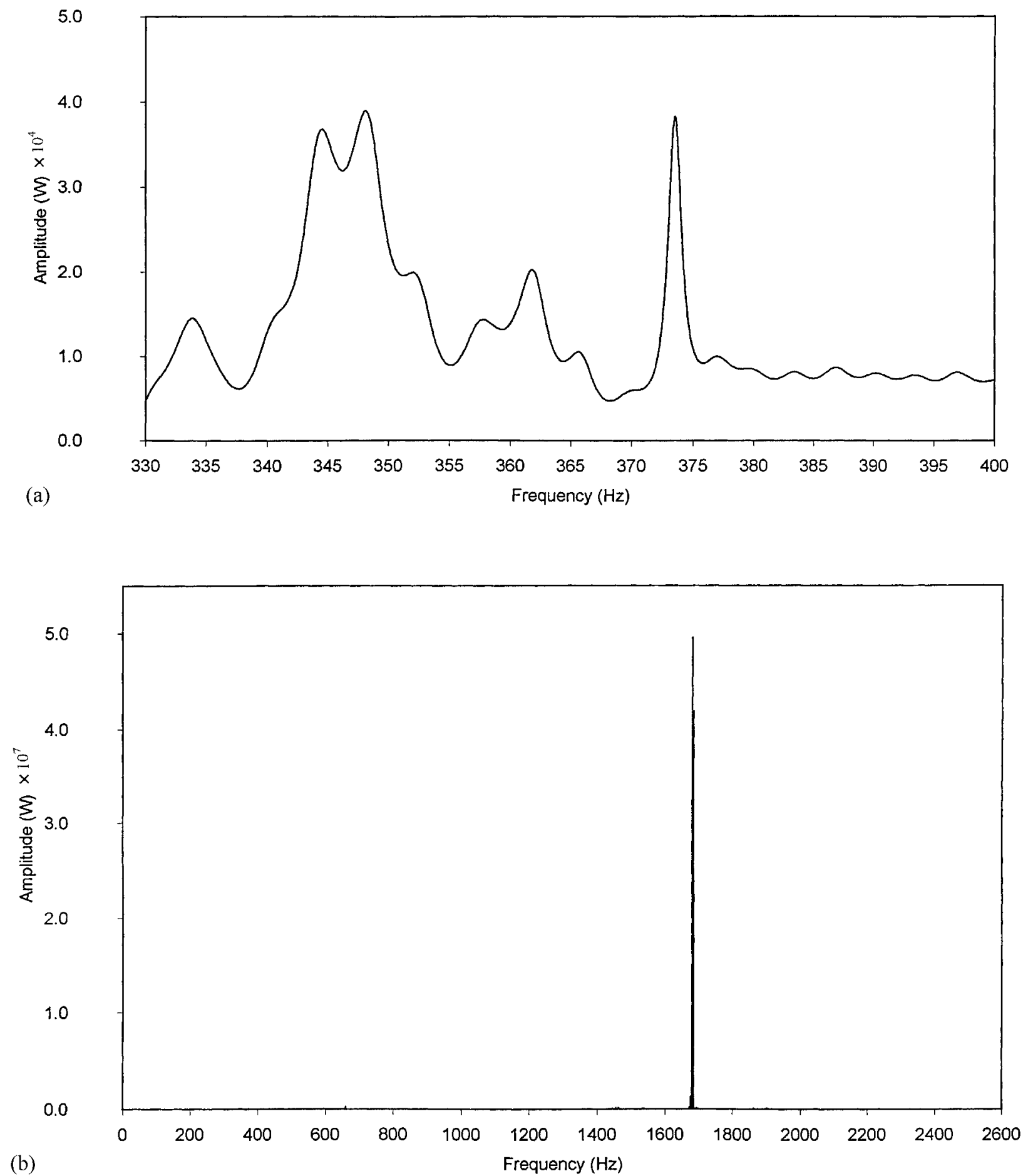

Fig. 11 (continued over) 


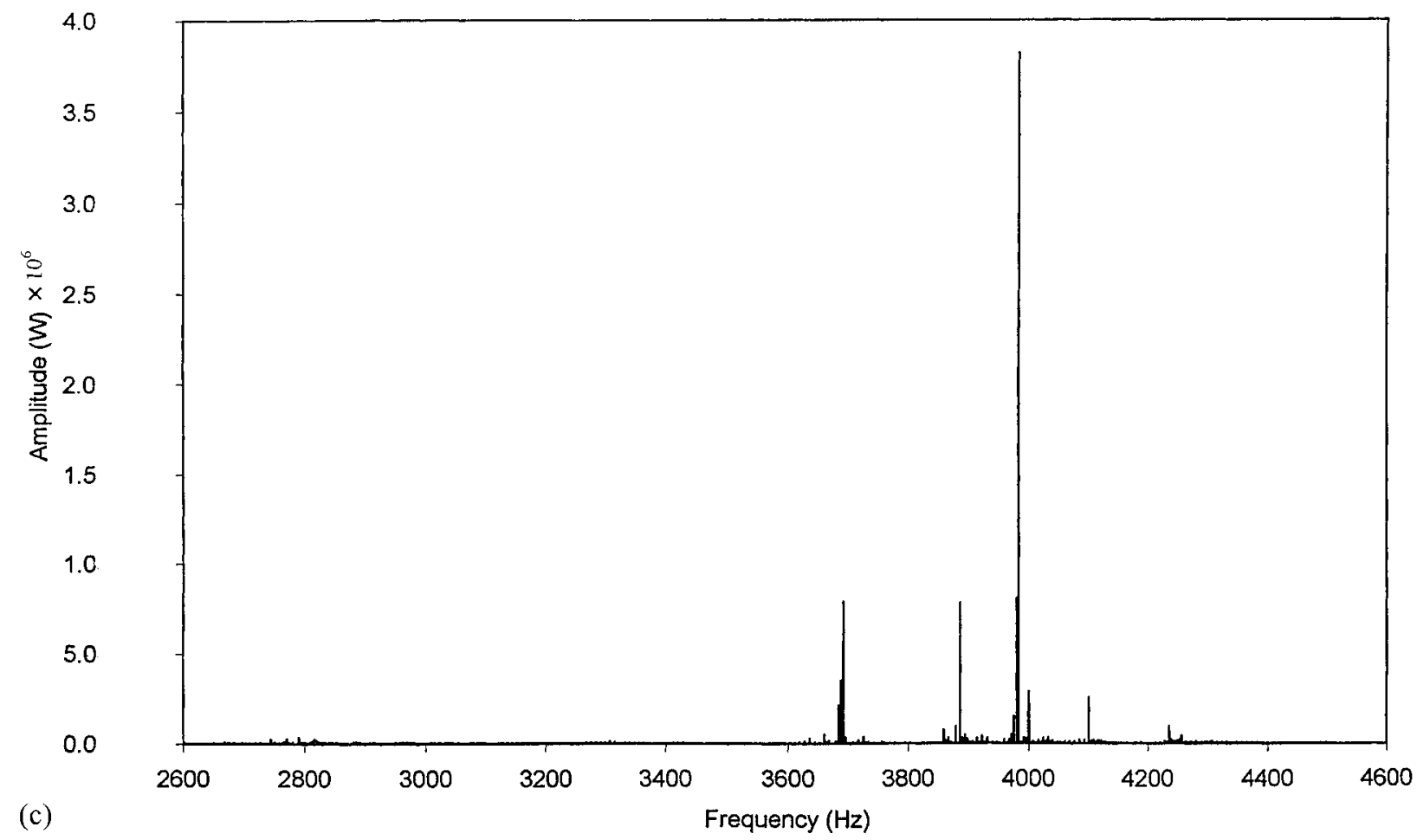

Fig. 11 Spectrum of vibration of the rear driveshaft tube: (a) first coupled structural-acoustic mode; (b) highest contribution at $1700 \mathrm{~Hz}$; (c) high axial compressioning modes

of the rear tube (see Fig. 11a), predicted numerically by the boundary element method at $390 \mathrm{~Hz}[\mathbf{8 , 9}, \mathbf{1 9}]$. The mid-range of structural spectral response at around $1700 \mathrm{~Hz}$ (see Fig. 10b) has also been obtained by finite element analysis in reference [10], and referred to previously (also see the contribution at $1860 \mathrm{~Hz}$ in Fig. 4). The higher structural modes in Fig. 11c correspond to the axial compressioning modes, reported above in the region $3250-3750 \mathrm{~Hz}$.

\section{ACKNOWLEDGEMENTS}

The authors wish to express their gratitude to Ford Motor Company for the financial support extended to this research project. The signal processing techniques employed in this analysis have been refined under the OPORTO Thematic Network for machine dynamics, funded by the European Commission. The support of the Commission is gratefully acknowledged.

\section{REFERENCES}

1 Krenz, R. Vehicle response to throttle tip in/tip out. SAE paper 850967, 1985.
2 Biermann, J. W. and Hagerodt, B. Investigation into the clonk phenomenon in vehicle transmission-measurement, modelling and simulation. Proc. Instn Mech. Engrs, Part K, Journal of Multi-body Dynamics, 1999, 213(K1), 53-60.

3 Menday, M. T., Rahnejat, H. and Ebrahimi, M. Clonk: an onomatopoeic response in torsional impact of automotive drivelines. Proc. Instn Mech. Engrs, Part D, Journal of Automobile Engineering, 1999, 213(D4), 349357.

4 Rabeih, E. M. A. and Crolla, D. A. Intelligent control of clutch judder and shunt phenomena in vehicle drivelines. Int. J. Veh. Des., 1996, 17(3), 318-332.

5 Centea, D. N., Rahnejat, H. and Menday, M. T. The influence of interface coefficient of friction upon propensity to judder in automotive clutches. Proc. Instn Mech. Engrs, Part D, Journal of Automobile Engineering, 1999, 213(D3), 245-258.

6 Rahnejat, H., Centea, D. and Kelly, P. Non-linear multibody dynamic analysis for the study of in-cycle vibrations (whoop) of cable operated clutch systems. In Proceedings of 30th ISATA, Florence, Italy, June 1997, pp. 245-252.

7 Kelly, P., Rahnejat, H., Biermann, J. W. and Hagerodt, B. Combining design of experiments and modelling techniques to resolve complex clutch pedal noise and vibration. In IMechE Conference Transactions of European Conference on Vehicle Noise and Vibration, May 1998, pp. 297-309 (Mechanical Engineering Publications, London).

8 Arrundale, D., Hussain, K., Rahnejat, H. and Menday, M. T. Acoustic response of driveline pieces under 
impacting loads (clonk). In Proceedings of 31st ISATA, Dusseldorf, June 1998, pp. 319-331.

9 Arrundale, D., Rahnejat, H. and Menday, M. T. Multibody dynamics of automobile drivelines: an investigation into the interaction between shuffle and clonk. In Proceedings of 32nd ISATA, Vienna, Austria, June 1999.

10 Kelly, P., Menday, M., Rahnejat, H. and Ebrahimi, M. Powertrain refinement: a combined experimental and multibody dynamics analysis approach. In 8th Aachen Colloquium, Aachen, Germany, October 1999.

11 Kelly, P. Multi-body dynamic analysis of engine induced automotive clutch pedal vibration. $\mathrm{PhD}$ thesis, University of Bradford, June 1999.

12 Menday, M. T. Torsional impact in an automotive vehicle driveline. MSc thesis, University of Bradford, December 1997.

13 Hrovat, D. Influence of drivetrain/chassis dynamics on tip in and back out driveability. Ford Motor Company Internal Report, 1989.

14 Tobler, W. and Tsangerides, M. Dynamic behaviour of a torque converter with centrifugal bypass clutch. SAE paper 850461, 1985.

15 Tsangerides, M., Tobler, W. and Heerman, C. Interactive computer simulation of drivetrain dynamics. SAE paper 850978, 1985.

16 Petri, H. and Heldingsfeld, D. The hydraulic torsion damper-a new concept for vibration damping in powertrains. SAE paper 892477, 1989.

17 Arnold, R. and Warburton, G. Flexural vibrations of the walls of thin cylindrical shells having freely supported ends. Proc. R. Soc., 1949.

18 Forsberg, K. Influence of boundary conditions on the modal characteristics of thin cylindrical shells. AIAA paper, 1964.

19 Arrundale, D. P. Elasto-multibody dynamic analysis applied to noise, vibration and harshness in powertrain systems. MPhil thesis, University of Bradford, June 1998.

20 Jenkins, G. M. and Watts, D. G. Spectral Analysis and its Applications, 1968 (Holden-Day, San Francisco).

21 Parzen, E. Mathematical considerations in the estimation on spectra. Technometrics, 1961, 3, 167-190.

22 Parzen, E. Statistical spectral analysis (single channel case). Technical Report 1, Department of Statistics, Stanford University, California, June 1968.

23 Kay, S. M. and Marple, S. L. Spectrum analysis: a modern perspective. Trans. IEEE, 1981, 69(11).

24 Burg, J. P. Maximum entropy spectral analysis. In Proceedings of 37th Meeting of Society of Exploration Geophysicists, Oklahoma City, Oklahoma, 31 October 1967.

25 Burg, J. P. Maximum entropy spectral analysis. $\mathrm{PhD}$ dissertation, Department of Geophysics, Stanford University, Stanford, California, May 1975.

26 Anderson, N. O. On the calculation of filter coefficients for maximum entropy spectral analysis. Geophysics, February 1974, 39, 69-72.

27 Barnard, T. E. The maximum entropy spectrum and the Burg technique. Technical Report 1, Advanced Signal Processing, Texas Instruments, prepared for Office of Naval Research, ALEX(03)-TR-75-01, 25 June 1975.

28 Box, G. E. P. and Jenkins, G. M. Time Series Analysis:
Forecasting and Control, 1970 (Holden-Day, San Francisco, California).

29 Datta, A. K. Comments on the complex form of the maximum entropy method for spectral estimation. Proc. IEEE, August 1977, 65, 1219-1220.

30 Fougere, P. F., Zawalic, E. J. and Radoski, H. R. Spontaneous line splitting in maximum entropy power spectrum analysis. Physics Earth Planet. Interiors, August 1976, 12, 201-207.

31 Fougere, P. F. A solution to the problem of spontaneous line splitting in maximum entropy power spectrum analysis. Geophys. Res., March 1977, 82, 1051-1054.

32 Cybenko, G. Round-off error propagation in Durbin's, Livenson's, and Trench's algorithms. In IEEE International Conference on Acoustics, Speech, and Signal Processing, pp. 498-501, 1979.

33 Durbin, J. The fitting of time series models. Rev. Inst. In Stat., 1960, 28, 233-244.

34 Shanks, J. L. Recursion filters for digital processing. Geophysics, 1967, 32(1), 33-51.

35 Therrien, C. W. Discrete Random Signals and Statistical Signal Processing, 1992 (Prentice-Hall, Englewood Cliffs, New Jersey).

36 Akaike, H. Fitting auto-regressive models for prediction. Ann. Inst. Statist. Math., 1969, 21, 243-247.

37 Akaike, H. Power spectrum estimation through autoregression model fitting. Ann. Inst. Statist. Math., 1969, 21, 407-419.

38 Akaike, H. On a semi-automatic power spectrum estimation procedure. In Proceedings of 3rd Hawaii International Conference on System Sciences, 1970, Part 2, pp. 974977.

39 Akaike, H. Statistical predictor identification. Ann. Inst. Statist. Math., 1970, 22, 203-217.

40 Akaike, H. Auto-regressive model fitting for control. Ann. Inst. Statist. Math., 1971, 23, 163-180.

41 Akaike, H. Use of an information theoretic quantity for statistical model identification. In Proceedings of 5th Hawaii International Conference on System Sciences, 1113 January 1972 , pp. 249-250.

42 Akaike, H. A new look at the statistical model identification. IEEE Trans. Autom. Control, December 1974, AC-19, 716-723.

43 Newland, D. E. Wavelet analysis of vibration. 1. Theory. Trans. ASME, J. Acoust. and Vibr., 1994, 116(4), 409416.

$44 \mathbf{~ L i , ~ C . ~ J . ~ a n d ~ M a , ~ J . ~ W a v e l e t ~ d e c o m p o s i t i o n ~ o f ~ v i b r a t i o n s ~}$ for detection of bearing-localized defects. NDT Int., 1997, 30(3), 143-149.

45 Mallat, S. A theory for multi-resolution signal decomposition: the wavelet representation. IEEE Trans. Pattern Anal. and Mach. Intell., 1989, 11, 674-693.

46 Daubechies, I. The wavelet transform time-frequency localization and signal analysis. IEEE Trans. Inf. Theory, 1990, 36(5), 961-1005.

47 Newland, D. E. An Introduction to Random Vibrations and Spectral and Wavelet Analysis, 3rd edition, 1993.

48 Misiti, M., Misiti, Y., Oppenheim, G. and Poggi, J. M. Wavelet Toolbox for Use with Matlab, 1997.

49 Strang, G. and Nguyen, T. Wavelets and Filter Banks, 1995 (Wellesley-Cambridge Press). 


\section{APPENDIX 1}

\section{Burg's method}

Burg's method is based on the Levinson recursion and the lattice structure for the model and has proven to be effective in a number of practical applications. The Burg procedure is a recursive procedure, where at each step in the recursion process a single reflection coefficient is estimated. The $p$ th reflection coefficient is chosen in order to minimize the sum of the forward and backward squared prediction errors:

$$
\boldsymbol{S}_{p}^{\mathrm{fb}}=\sum_{n=p}^{N_{\mathrm{s}}-1}\left(\left|\varepsilon_{p}[n]\right|^{2}+\left|\boldsymbol{\varepsilon}_{p}^{\mathrm{b}}[n]\right|^{2}\right)
$$

It should be noted that the forward and backward prediction problems are statistically identical and that there is no reason to favour one over the other in estimating the prediction error. Therefore, both $\varepsilon_{p}$ and $\varepsilon_{p}^{\mathrm{b}}$ should be included for the minimization criterion.

Burg's method can be derived as follows. Consider running the $p$ th order forwards and backwards over the available data in order to generate the error terms needed in equation (14). According to the lattice equation, these terms satisfy the order recursions as

$$
\begin{aligned}
{\left[\begin{array}{c}
\varepsilon_{p}[p] \\
\varepsilon_{p}[p+1] \\
\vdots \\
\varepsilon_{p}\left[N_{\mathrm{s}}-1\right]
\end{array}\right]=} & {\left[\begin{array}{c}
\varepsilon_{p-1}[p] \\
\varepsilon_{p-1}[p+1] \\
\vdots \\
\varepsilon_{p-1}\left[N_{s}-1\right]
\end{array}\right] } \\
& -\boldsymbol{\gamma}_{p}^{*}\left[\begin{array}{c}
\varepsilon_{p-1}^{\mathrm{b}}[p-1] \\
\varepsilon_{p-1}^{\mathrm{b}}[p] \\
\vdots \\
\varepsilon_{p-1}^{\mathrm{b}}\left[N_{\mathrm{s}}-2\right]
\end{array}\right]
\end{aligned}
$$

and

$$
\begin{aligned}
{\left[\begin{array}{c}
\varepsilon_{p}^{\mathrm{b}}[p] \\
\varepsilon_{p}^{\mathrm{b}}[p+1] \\
\vdots \\
\varepsilon_{p}^{\mathrm{b}}\left[N_{\mathrm{s}}-1\right]
\end{array}\right]=} & {\left[\begin{array}{c}
\varepsilon_{p-1}^{\mathrm{b}}[p-1] \\
\varepsilon_{p-1}^{\mathrm{b}}[p] \\
\vdots \\
\varepsilon_{p-1}^{\mathrm{b}}\left[N_{\mathrm{s}}-2\right]
\end{array}\right] } \\
& -\boldsymbol{\gamma}_{p}^{\prime *}\left[\begin{array}{c}
\varepsilon_{p-1}[p] \\
\varepsilon_{p-1}[p+1] \\
\vdots \\
\varepsilon_{p-1}\left[N_{\mathrm{s}}-1\right]
\end{array}\right]
\end{aligned}
$$

where

$$
\begin{gathered}
\varepsilon_{p}=\left[\begin{array}{c}
\varepsilon_{p}[p] \\
--- \\
\\
\boldsymbol{e}_{p}^{\mathrm{f}}
\end{array}\right] ; \quad \boldsymbol{\varepsilon}_{p}^{\mathrm{b}}=\left[\begin{array}{c}
e_{p}^{\mathrm{b}} \\
\\
----- \\
\varepsilon_{p}^{\mathrm{b}}\left[N_{\mathrm{s}}-1\right]
\end{array}\right] \\
\boldsymbol{e}_{p}^{\mathrm{f}}=\left[\begin{array}{c}
\varepsilon_{p}[p+1] \\
\varepsilon_{p}[p+2] \\
\vdots \\
\varepsilon_{p}^{\mathrm{b}}[p] \\
\varepsilon_{p}^{\mathrm{b}}[p+1] \\
\vdots \\
\varepsilon_{p}^{\mathrm{b}}\left[N_{\mathrm{s}}-1\right]
\end{array}\right] ; \quad \boldsymbol{e}_{p}^{\mathrm{b}}=\left[\begin{array}{c} 
\\
\left.\varepsilon_{\mathrm{s}}-2\right]
\end{array}\right]
\end{gathered}
$$

Since $\boldsymbol{\gamma}_{p}^{\prime}=\boldsymbol{\gamma}_{p}^{*}$, the lattice relations (15) and (16) can be written as

$$
\begin{gathered}
\boldsymbol{\varepsilon}_{p}=\left[\begin{array}{c}
\times \\
-- \\
\\
e_{p}^{\mathrm{f}}
\end{array}\right]=\boldsymbol{e}_{p-1}^{\mathrm{f}}-\boldsymbol{\gamma}_{p}^{*} \boldsymbol{e}_{p-1}^{\mathrm{b}} \\
\varepsilon_{p}^{\mathrm{b}}=\left[\begin{array}{c}
e_{p}^{\mathrm{b}} \\
\\
-- \\
\times
\end{array}\right]=\boldsymbol{e}_{p-1}^{\mathrm{b}}-\boldsymbol{\gamma}_{p} \boldsymbol{e}_{p-1}^{\mathrm{f}}
\end{gathered}
$$

With these definitions and relations, equation (17) can be expressed as

$$
\begin{aligned}
\boldsymbol{S}_{p}^{\mathrm{fb}}= & \left\|\boldsymbol{\varepsilon}_{p}\right\|^{2}+\left\|\boldsymbol{\varepsilon}_{p}^{\mathrm{b}}\right\|^{2} \\
= & \left(\boldsymbol{e}_{p-1}^{\mathrm{f}}-\boldsymbol{\gamma}_{p}^{*} \boldsymbol{e}_{p-1}^{\mathrm{b}}\right)^{* \mathrm{~T}}\left(\boldsymbol{e}_{p-1}^{\mathrm{f}}-\boldsymbol{\gamma}_{p}^{*} \boldsymbol{e}_{p-1}^{\mathrm{b}}\right) \\
& +\left(\boldsymbol{e}_{p-1}^{\mathrm{b}}-\boldsymbol{\gamma}_{p} \boldsymbol{e}_{p-1}^{\mathrm{f}}\right)^{* \mathrm{~T}}\left(\boldsymbol{e}_{p-1}^{\mathrm{b}}-\boldsymbol{\gamma}_{p} \boldsymbol{e}_{p-1}^{\mathrm{f}}\right) \\
= & \left(1+\boldsymbol{\gamma}_{p} \boldsymbol{\gamma}_{p}^{*}\right)\left(\left\|\boldsymbol{e}_{p-1}^{\mathrm{f}}\right\|^{2}+\left\|\boldsymbol{e}_{p-1}^{\mathrm{b}}\right\|^{2}\right) \\
& -2 \boldsymbol{\gamma}_{p}^{*}\left(\boldsymbol{e}_{p-1}^{\mathrm{f}}\right)^{* \mathrm{~T}} \boldsymbol{e}_{p-1}^{\mathrm{b}}-2 \boldsymbol{\gamma}_{p}\left(\boldsymbol{e}_{p-1}^{\mathrm{b}}\right)^{* \mathrm{~T}} \boldsymbol{e}_{p-1}^{\mathrm{f}}
\end{aligned}
$$

Then, using the expressions in a scalar form of the complex gradient provides the necessary condition:

$$
\begin{aligned}
\nabla_{\boldsymbol{\gamma}_{p}^{*}} \boldsymbol{S}_{p}^{\mathrm{fb}} & =\boldsymbol{\gamma}_{p}\left(\left\|\boldsymbol{e}_{p-1}^{\mathrm{f}}\right\|^{2}+\left\|\boldsymbol{e}_{p-1}^{\mathrm{b}}\right\|^{2}\right)-2\left(\boldsymbol{e}_{p-1}^{\mathrm{f}}\right)^{* \mathrm{~T}} \boldsymbol{e}_{p-1}^{\mathrm{b}} \\
& =0
\end{aligned}
$$


or

$$
\boldsymbol{\gamma}_{p}=\frac{2\left(\boldsymbol{e}_{p-1}^{\mathrm{f}}\right) * \mathrm{~T}}{\boldsymbol{e}_{p-1}^{\mathrm{b}}}
$$

The form of this equation guarantees that the estimated reflection coefficient satisfies the condition $\left|\boldsymbol{\gamma}_{p}\right| \leqslant 1$. These are iterated for $p=1,2,3, \ldots, P$, starting from the initial conditions

$$
\left[\begin{array}{c}
\times \\
-- \\
e_{0}^{\mathrm{f}}
\end{array}\right]=\left[\begin{array}{c}
e_{0}^{\mathrm{b}} \\
\\
-- \\
\times
\end{array}\right]=\left[\begin{array}{c}
x[0] \\
x[1] \\
\vdots \\
x\left[N_{\mathrm{s}}-1\right]
\end{array}\right]
$$

The algorithm is quite simple in this form. At each stage of iteration the reflection coefficient is formed from equation (18). The vectors are then combined as in (17), the elements denoted by $\times$ are omitted and the steps are repeated. Thus, the vectors $\boldsymbol{e}_{p}^{\mathrm{f}}$ and $\boldsymbol{e}_{p}^{\mathrm{b}}$ decrease in size at each iteration. An estimate for the prediction error variance can be computed by the additional recursion

$$
\sigma_{\varepsilon_{p}}^{2}=\left(1-\left|\boldsymbol{\gamma}_{p}\right|^{2}\right) \sigma_{\varepsilon_{p-1}}^{2}
$$

and then the MA coefficients can be computed from the recursion

$$
\boldsymbol{a}_{p}=\left[\begin{array}{c}
a_{p-1} \\
\\
-- \\
0
\end{array}\right]-\boldsymbol{\gamma}_{p}^{*}\left[\begin{array}{c}
0 \\
-- \\
\\
\tilde{a}_{p-1}^{*}
\end{array}\right]
$$

\section{APPENDIX 2}

\section{Shanks' method}

This next procedure is due to Shanks [34] and the combination of this with the least-squares procedure for finding the AR parameters is sometimes referred to as Shanks' method. The goal is to represent the given data in the form

$$
\boldsymbol{X}(z) \approx \frac{\boldsymbol{B}(z)}{\boldsymbol{A}(z)}
$$
where $\boldsymbol{A}(z)$ has already been determined using Burg's method, set out in Appendix 1. Define

$$
\boldsymbol{H}_{A}(z)=\frac{1}{\boldsymbol{A}(z)} \quad \text { and } \quad \boldsymbol{X}(z) \approx \boldsymbol{B}(z) \boldsymbol{H}_{A}(z)
$$

Let $\boldsymbol{h}_{A}[n]$ be the sequence corresponding to $\boldsymbol{H}_{A}(z)$. This sequence is actually the impulse response, corresponding to the partial system $1 / \boldsymbol{A}(z)$. The approximation problem can now be thought of as shown in Fig. 12.

The error in the signal domain is given by

$$
\boldsymbol{e}_{B}[n]=\boldsymbol{x}[n]-\boldsymbol{h}_{A}[n] * \boldsymbol{b}[n]
$$

If the filter $\boldsymbol{B}(z)$ is chosen in order to minimize the sum of squared errors, then

$$
\boldsymbol{S}_{B}=\sum_{n=0}^{N_{\mathrm{s}}-1}\left|\boldsymbol{e}_{B}[n]\right|^{2}
$$

In fact, this is exactly the least-squares Wiener filtering problem. The problem can be represented as

$$
\boldsymbol{H}_{A} \boldsymbol{b} \stackrel{1 \mathrm{~s}}{=} \boldsymbol{x}
$$

where

$$
\boldsymbol{H}_{A}=\left[\begin{array}{cccc}
h_{A}[0] & 0 & \ldots & 0 \\
h_{A}[1] & h_{A}[0] & \ldots & 0 \\
\vdots & \vdots & \ldots & \vdots \\
h_{A}[Q] & h_{A}[Q-1] & & h_{A}[0] \\
\vdots & \vdots & \ldots & \vdots \\
h_{A}\left[N_{\mathrm{s}}-1\right] & h_{A}\left[N_{\mathrm{s}}-2\right] & \ldots & h_{A}\left[N_{\mathrm{s}}-Q-1\right]
\end{array}\right]
$$

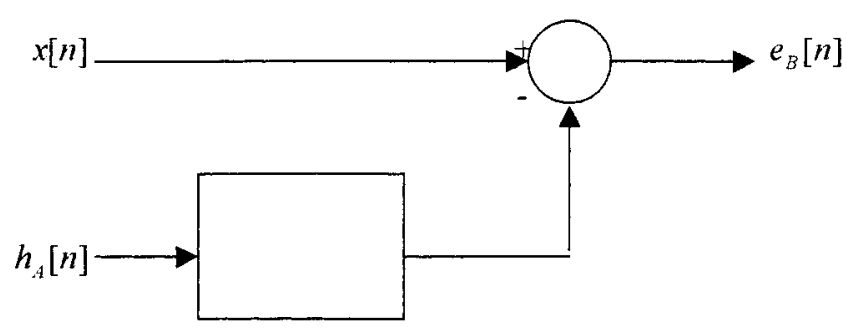

Fig. 12 The approximation problem Proc Instn Mech Engrs Vol 215 Part K 
and

$$
\boldsymbol{x}=\left[\begin{array}{c}
x[0] \\
x[1] \\
\vdots \\
x[\boldsymbol{Q}] \\
\vdots \\
x\left[N_{\mathrm{s}}-1\right]
\end{array}\right]
$$

and $b=0$. As an alternative the lower limit in equation (25) can be set to $Q$, in which case equations (27) and (28) will be missing from the first $Q$ rows. The solution is then obtained as

$$
\boldsymbol{b}=\boldsymbol{H}_{A}^{-1} \boldsymbol{x}
$$

The terms needed in the sequence, $\boldsymbol{h}_{A}[n]$, can be obtained from the recursive difference equation

$$
\boldsymbol{h}_{A}[n]=-a_{1} \boldsymbol{h}_{A}[n-1]-\cdots-a_{p} \boldsymbol{h}_{A}[n-P]+\delta[n]
$$

Alternatively, it may be feasible to find the roots of $\boldsymbol{A}(z)$ and develop an analytic expression for $\boldsymbol{h}_{A}[n]$ (at least for some simple cases). 